\title{
Estudos complementares sobre a toxidez de Lantana camara (Verbenaceae) em bovinos ${ }^{1}$
}

\author{
Carlos Hubinger Tokarnia ${ }^{2}$, Anibal Guillermo Armién ${ }^{3}$, Severo Sales de Barros ${ }^{4}$, Paulo \\ Vargas Peixoto ${ }^{2}$ e Jürgen Döbereiner ${ }^{3}$
}

\begin{abstract}
Tokarnia C.H., Armién A.G., Barros S.S., Peixoto P.V. \& Döbereiner J. 1999. [Complementary studies on the toxicity of Lantana camara (Verbenaceae) in cattle.] Estudos complementares sobre a toxidez de Lantana camara (Verbenaceae) em bovinos. Pesquisa Veterinária Brasileira 19(3/4):128-132. Projeto Sanidade Animal Embrapa/UFRRJ, Km 47, Seropédica, RJ, 23851-970, Brazil.

An outbreak of poisoning by Lantana camara var. aculeata in cattle was diagnosed in the county of Quatis, State of Rio de Janeiro. The animals, after travelling by foot, were put, hungry, for a few days, on a pasture highly infested by the plant. The toxicity of the plant was proved experimentally in cattle; also experiments to see how far the plant has cumulative properties, were performed. The plant caused lethal poisoning when given as a single dose of $40 \mathrm{~g} / \mathrm{kg} ; 20 \mathrm{~g} / \mathrm{kg}$ caused severe poisoning, $10 \mathrm{~g} / \mathrm{kg}$ slight or no poisoning and $5 \mathrm{~g} / \mathrm{kg}$ failed to provoke symptoms. A lethal result was produced also when $10 \mathrm{~g} / \mathrm{kg}$ per day was given over 4 days. The administration of $5 \mathrm{~g} / \mathrm{kg}$ per day caused severe poisoning when fed over 5 days to two calves. The dose of $2.5 \mathrm{~g} / \mathrm{kg}$ fed daily over 7 or 9 days also produced severe poisoning in two calves; in another calf, severe symptoms were produced only after feeding $2.5 \mathrm{~g} / \mathrm{kg}$ per day for 19 days; still another calf showed no symptoms after 32 days of feeding $2,5 \mathrm{~g} / \mathrm{kg}$ per day, although twice the lethal dose had been fed by this time. A dose of $1.25 \mathrm{~g} / \mathrm{kg}$ per day over 34 days also failed to produce any symptoms.
\end{abstract}

INDEX TERMS: Poisonous plants, plant poisoning, photosensitization, Lantana camara, Verbenaceae, pathology, cattle.

RESUMO.- Descreve-se, no município de Quatis, RJ, a ocorrência de um surto de intoxicação por Lantana camara var. aculeata em bovinos, caracterizado por acentuada icterícia, lesões de fotossensibilização, constipação e edema subcutâneo dos membros. A reprodução experimental da doença, com êxito letal, através da administração de dose única de $40 \mathrm{~g} / \mathrm{kg}$ de L. camara var. aculeata, confirmou a planta como causa do surto; doses únicas de $20 \mathrm{~g} / \mathrm{kg}, 10 \mathrm{~g} / \mathrm{kg}$ e $5 \mathrm{~g} / \mathrm{kg}$ causaram respectivamente, grave intoxicação, leve intoxicação e ausência de sintomas. Experimentos com doses repetidas permitem concluir que essa planta apresenta efeito

${ }^{1}$ Aceito para publicação em 14 de janeiro de 1999.

${ }^{2}$ Depto Nutrição Animal e Pastagem, Universidade Federal Rural do Rio de Janeiro (UFRRJ), Km 47, Seropédica, RJ 23851-970; bolsistas do CNPq (305010/76-VT e 302342/86-9).

${ }^{3}$ Projeto Sanidade Animal Embrapa/UFRRJ, Km 47, Seropédica, RJ 23851970; bolsista do CNPq (350256/97-7 e 309294/88-1).

${ }^{4}$ Pesquisador visitante do CNPq, Depto Patologia Animal, Faculdade de Veterinária, Universidade Federal de Pelotas, Pelotas, RS 96010-900. acumulativo, quando ingerida em doses diárias de $10 \mathrm{~g} / \mathrm{kg}$ (1/ 4 da dose letal); a administração de quatro doses de $5 \mathrm{~g} / \mathrm{kg}$ (1/8 da dose letal) ou de oito doses de $2,5 \mathrm{~g} / \mathrm{kg}$ (1/16 da dose letal) reproduziram o quadro grave de intoxicação. Subdoses menores, de $1,25 \mathrm{~g} / \mathrm{kg}$ (1/32 da dose letal), administradas durante 34 dias, não produziram quaisquer sinais clínicos. Os exames histológicos dos casos naturais e experimentais revelaram, além de bilestase, alterações regressivas nos hepatócitos e no epitélio dos túbulos renais.

TERMOS DE INDEXAÇÃO: Plantas tóxicas, intoxicação por planta, fotossensibilização, Lantana camara, Verbenaceae, patologia, bovinos.

\section{INTRODUÇÃO}

Lantana camara, arbusto bastante conhecido por induzir a fotossensibilização hepatógena, é representada por muitas variedades (taxa), tóxicas ou não. Segundo Seawright (1965), as quantidades necessárias para causar intoxicação variam sobretudo com o taxa (fator genético) e, em menor grau, com a procedência. 
De acordo com a literatura e com observações próprias, surtos de intoxicação por Lantana spp no Brasil, embora graves, são raros, pois só ocorrem quando os animais estão famintos e sendo transferidos de pasto ou região, além de, é claro, de tratar-se de espécie ou de variedade tóxica de Lantana que exista em abundância.

Foram descritos surtos de intoxicação por Lantana spp nos municípios de Cáceres, MT, de Cabo Frio, RJ (Tokarnia et al. 1984) e de Canoinhas, SC (Riet-Correa et al. 1984), todos com comprovação experimental da toxidez das lantanas envolvidas nos surtos.

Assim, Tokarnia et al. (1984) administraram Lantana tiliaefolia Cham. (coletada em Mato Grosso, mun. Cáceres) e Lantana camara var. nivea (Vent.) L.H. Bailey (coletada no Estado do Rio de Janeiro, mun. Cabo Frio), em estado fresco, por via oral, a bovinos. Doses únicas de 30 e $40 \mathrm{~g} / \mathrm{kg}$ ou doses repetidas de $10 \mathrm{~g} / \mathrm{kg}$, durante 4 a 5 dias, causaram graves sintomas com morte de parte dos animais, enquanto que administração única de $20 \mathrm{~g} / \mathrm{kg}$ provocou sintomas moderados. Dose única de $10 \mathrm{~g} / \mathrm{kg}$ não causou sintomas de intoxicação, porém doses de $5 \mathrm{~g} / \mathrm{kg}$ por dia, administradas a um bezerro, durante 22 dias seguidos, produziram leves sintomas de intoxicação. Desta maneira, as duas lantanas submetidas à experimentação demonstraram possuir efeito acumulativo quando a dose letal foi subdividida em 4 ou 5 doses diárias, mas não mais quando administrada em doses diárias correspondentes a oitava parte da dose letal.

Em outro estudo experimental, Riet-Correa et al. (1984) administraram Lantana glutinosa Poepp. (coletada em Santa Catarina), em estado fresco, por via oral, a bovinos, tendo provocado grave quadro de fotossensibilização e morte dos animais com doses únicas de $10 \mathrm{~g} / \mathrm{kg}, 20 \mathrm{~g} / \mathrm{kg}$ e $40 \mathrm{~g} / \mathrm{kg}$.

Brito \& Tokarnia (1995) verificaram que ovinos têm a mesma sensibilidade que bovinos à intoxicação por Lantana camara var. aculeata, procedente do município de Quatis, RJ. Tanto a planta fresca, como a dessecada, causaram doença grave com fotossensibilização e morte de todos os ovinos na dosagem única de $40 \mathrm{~g} / \mathrm{kg}$ (planta fresca ou quantidade correspondente da planta dessecada); a dosagem de $10 \mathrm{~g} / \mathrm{kg}$, administrada durante 4 dias seguidos, também causou doença grave em quatro dos cinco animais, mas dois dos quatro animais severamente afetados se recuperaram.

Temos verificado que, normalmente, os bovinos pastam pequenas quantidades destas plantas, o que aparentemente não tem causado danos a sua saúde. Através de revisão da literatura, verifica-se que foram realizados poucos estudos experimentais de administrações repetidas para verificar o efeito acumulativo das lantanas, tanto em bovinos como em ovinos. Além dos poucos experimentos de administrações repetidas realizados no Brasil, acima mencionados, há os experimentos de Gopinath \& Ford (1969), que administraram doses únicas (planta dessecada) de $10 \mathrm{~g} / \mathrm{kg}$ de L. camara (dois animais), de $5 \mathrm{~g} / \mathrm{kg}$ em dois dias seguidos (4 animais) e de $2 \mathrm{~g} /$ $\mathrm{kg}$ por 5 dias seguidos ( 2 animais), vindo a adoecer apenas os animais dos dois primeiros grupos. Com base nesses experimentos estes autores sugerem que os casos naturais da intoxicação por lantana devem-se ao rápido consumo de grandes quantidades da planta e não pela ingestão de doses repetidas, já que a planta não possuiria efeito acumulativo.

O presente estudo tem por objetivos descrever o surto de intoxicação por Lantana camara var. aculeata em bovinos que ocorreu em Quatis, RJ, comprovar experimentalmente a toxidez dessa lantana, com determinação da dose letal e verificar até que ponto essa lantana possui efeito acumulativo.

\section{MATERIAL E MÉTODOS}

O estudo do surto consistiu na coleta do histórico, em exames clínicopatológicos e na inspeção dos pastos envolvidos.

A planta usada, identificada como Lantana camara var. aculeata (L.) Moldenke, da família Verbenaceae, em todos os experimentos procedia dos pastos do sítio no distrito de Falcão onde ocorreu o surto de intoxicação no município de Quatis, RJ. Os experimentos sempre eram iniciados no mesmo dia ou no dia seguinte à coleta da planta; as folhas a serem administradas nos dias posteriores, eram guardadas, já pesadas, na geladeira, para um período de até 14 dias.

Foram usadas dosagens únicas da planta para verificar o seu grau de toxidez. Nos experimentos para verificar o efeito acumulativo da planta, foram usados sucessivamente doses que correpondiam a metade das dosagens precedentes, começando com um quarto da dose letal. O planejamente sempre previa a administração de dosagens fraccionadas até que se completasse pelo menos a dose letal. Mas as administrações eram interrompidas, quando os animais mostravam anorexia, o que aconteceu diversas vezes.

Foram utilizados 15 bezerros, de ambos os sexos, com idade de 1 a 2 anos, mestiços Holandês Preto e Branco, com peso variando entre 127 e $272 \mathrm{~kg}$, clinicamento sadios.

Os animais eram mantidos em baias individuais e recebiam, pela manhã e à tarde, capim-elefante (Penisetum purpureum) picado, cerca de um quilo de ração comercial e água à vontade. Entre 8:30 e 11:30 e 13:30 e 16:30h eram colocados em piquete ensolarado. Quando os sintomas de fotossensibilização ficavam evidentes e o estado de irritação muito grande, os animais eram soltos por períodos menores ou não mais eram soltos no piquete.

Os exames clínicos eram realizados pela manhã e à tarde ou, com mais frequência, à medida que se agravava o quadro; na fase terminal os animais eram observados continuamente. No caso de morte era realizada a necropsia com coleta de material para exames histopatológicos. As amostras para exames histopatológicos foram coletadas e fixadas em formol tamponado a $10 \%$, exceto o sistema nervoso central que foi fixado em formol a $20 \%$. As amostras coletadas foram processadas pelos métodos usuais, incluídas em parafina, cortadas a 5 micra de espessura e coradas pela hematoxilinaeosina (HE).

\section{RESULTADOS}

Estudo do surto de intoxicação em bovinos no município de Quatis, RJ

Em outubro de 1989 obtivemos o histórico, segundo o qual, um fazendeiro do município de Quatis, RJ, comprara 30 garrotes de aproximadamente 18 meses de idade no município de Passa Vinte, MG. Esses garrotes foram escolhidos no dia 31.9.89 e no dia seguinte, após terem permanecido 24 horas no local, foram conduzidos, a pé, até um sítio localizado no distrito de Falcão, RJ, onde chegaram às 10 horas e foram soltos no pasto, famintos. Dois dias depois, três animais já haviam adoecido; os demais foram levados para a fazenda em Quatis, onde chegaram às 19 horas. Em 4.10.89 
os garrotes estavam com o pêlo arrepiado, e nos dias seguintes, teriam apresentado febre a ponto de rachar a pele, além de terem as fezes ressequidas. Não adoeceram os bovinos da fazenda localizada em Passa Vinte, onde foram adquiridos os garrotes, nem o gado sediado no sítio em Falcão, com exceção dos 3 garrotes do lote adquirido e que foram deixados lá, e nem o gado na fazenda em Quatis.

Por ocasião de nossa visita à fazenda em Quatis, em 13.10.89, tinham adoecido 24 dos 30 garrotes adquiridos, dos quais, até aquela data, seis tinham morrido, cinco em Quatis e um dos três que ficaram no sítio em Falcão. Os seis garrotes mais afetados apresentavam acentuada icterícia, globos oculares retraídos, marcado emagrecimento, lesões de fotossensibilização em diversas partes da superfície do corpo, urina bem amarelada (aurea), fezes ressequidas, pêlos arrepiados e fraqueza. Foram confeccionados esfregaços de sangue desses animais, que, corados pelo Giemsa, não revelaram a presença de hematoprotozoários (ou outras alterações). Nos dois animais necropsiados, um no Instituto na véspera (necr. 17/89 em 12.10.89) e o outro na propriedade em Quatis (necr. 18/89 em 13.10.89), verificamos acentuada icterícia, edema gelatinoso subcutâneo nos membros e lesões de fotossensibilização na pele. Os exames histopatológicos destes dois animais (reg. SAP 24747 e 24748), revelaram além de bilestase, alterações degenerativas nos hepatócitos e nas células epiteliais dos túbulos uriníferos.

Na inspeção dos pastos verificou-se, que a pastagem no sítio em Falcão era escassa e que havia grande quantidade de Lantana camara var. aculeata, antes roçada e agora em abundante brotação, na maior parte comida pelo gado.

Por ocasião de uma visita à fazenda em Quatis em 20.5.92, fomos informados que morreram 22 dos 30 garrotes.
Estudos experimentais com Lantana camara var. aculeata, coletada no distrito de Falcão, município de Quatis, RJ

$\mathrm{O}$ delineamento dos experimentos e os principais resultados constam no Quadro 1. Nos experimentos de administração de doses únicas, observou-se que a dose de $5 \mathrm{~g} / \mathrm{kg}$ não causou o aparecimento de sintomas (0/1). A dose única de $10 \mathrm{~g} / \mathrm{kg}$ também não provocou sintomas em um bezerro, mas em outro leves sintomas (1/2). Já a dose única de $20 \mathrm{~g} / \mathrm{kg}$ causou nos dois bezerros usados intoxicação grave, mas ambos se recuperaram (2/2). A dose única de $40 \mathrm{~g} / \mathrm{kg}$ causou intoxicação grave; o animal foi sacrificado in extremis (1/1). Esta última dose foi considerada a dose letal.

A dose de $10 \mathrm{~g} / \mathrm{kg} / \mathrm{dia}$ administrada 4 vezes, completando $40 \mathrm{~g} / \mathrm{kg}$, causou intoxicação grave; o animal foi sacrificado in extremis - portanto, nesta dosagem a planta mostrou efeito acumulativo. A dose de $5 \mathrm{~g} / \mathrm{kg} / \mathrm{dia}$ repetida em dois bezerros 5 vezes, perfazendo um total de $25 \mathrm{~g} / \mathrm{kg}$ (era planejado completar pelos menos $40 \mathrm{~g} / \mathrm{kg}$ ) causou intoxicação grave, mas os animais se recuperaram - portanto a planta demonstrou também neste experimento efeito acumulativo. A dose de $2,5 \mathrm{~g} /$ $\mathrm{kg} / \mathrm{dia}$, repetida em um bezerro 9 vezes, perfazendo um total de $22,5 \mathrm{~g} / \mathrm{kg}$, em outro bezerro repetida 7 vezes, perfazendo um total de $17,5 \mathrm{~g} / \mathrm{kg}$ (nesses dois bezerros era planejado completar pelo menos $40 \mathrm{~g} / \mathrm{kg}$ ), e em um terceiro bezerro 19 vezes, perfazendo um total de $47,5 \mathrm{~g} / \mathrm{kg}$, também causou intoxicação grave, mas os animais se recuperaram. Pelos experimentos nos dois primeiros bezerros (5249 e 5287) ficou novamente evidente o efeito acumulativo da planta, porém no experimento com o terceiro bezerro este efeito não foi total; um quarto bezerro, que recebeu a dose de $2,5 \mathrm{~g} / \mathrm{kg} / \mathrm{dia}$ durante 32 dias, perfazendo o dobro da dose letal, não adoeceu portanto neste bovino a planta não demonstrou efeito acumulativo. A dose de $1,25 \mathrm{~g} / \mathrm{kg} / \mathrm{dia}$ repetida 34 vezes, perfazendo um pouco mais que a dose letal, não mais causou

Quadro 1. Intoxicação experimental em bovinos por Lantana camara var. aculeata procedente do sítio no distrito de Falcão, município de Quatis, RJ

\begin{tabular}{|c|c|c|c|c|c|c|c|c|c|}
\hline $\begin{array}{l}\text { Bovino } \\
\text { no. } \\
\text { (SAP) }\end{array}$ & $\begin{array}{l}\text { Peso } \\
\text { kg }\end{array}$ & $\begin{array}{c}\text { Data da }\left(1^{\mathrm{a}}\right) \\
\text { administração }\end{array}$ & $\begin{array}{l}\text { Dose } \\
\mathrm{g} / \mathrm{kg}\end{array}$ & $\begin{array}{l}\text { Número } \\
\text { de doses }\end{array}$ & $\begin{array}{l}\text { Início dos sintomas } \\
\text { após começo da } \\
\text { administração }\end{array}$ & $\begin{array}{l}\text { Evolução clínica } \\
\text { da intoxicação }\end{array}$ & $\begin{array}{l}\text { Intensidade da } \\
\text { intoxicação }\end{array}$ & $\begin{array}{c}\text { Morte após } \\
\text { começo da } \\
\text { administração }\end{array}$ & Recuperado \\
\hline $\begin{array}{c}4928 \\
(25806-09)\end{array}$ & 127 & 21.05 .92 & 10 & 4 & 24.05 .92 & 13 dias & $+++^{a}$ & $\begin{array}{c}05.06 .92 \text { (sacr. } \\
\text { in extremis) }\end{array}$ & - \\
\hline $\begin{array}{c}4923 \\
(25871-74)\end{array}$ & 176 & 22.05 .92 & 40 & 1 & 25.05 .92 & 16 dias & +++ & $\begin{array}{c}\text { 09.06.92(sacr. } \\
\text { in extremis) }\end{array}$ & - \\
\hline 5229 & 142 & 24.08 .95 & 5 & 5 & 28.08 .95 & 19 dias & +++ & - & 16.09 .95 \\
\hline 5230 & 136 & 24.08 .95 & 5 & 5 & 28.08 .95 & 11 dias & +++ & - & 08.09.95 \\
\hline 5273 & 190 & 18.09.96 & 5 & 1 & - & - & - & - & - \\
\hline 5270 & 197 & 18.09 .96 & 10 & 1 & 21.09.96 & 2 dias & + & - & 22.09 .96 \\
\hline 5528 & 272 & 18.09 .96 & 20 & 1 & 19.09.96 & 17 dias & +++ & - & 07.10 .96 \\
\hline 5249 & 162 & 13.06 .97 & 2,5 & 9 & 21.06.97 & 10 dias & +++ & - & 01.07.97 \\
\hline 5287 & 153 & 13.06 .97 & 2,5 & 7 & 17.06 .97 & 12 dias & +++ & - & 28.06 .97 \\
\hline 5292 & 138 & 14.05 .98 & 1,25 & 34 & - & - & - & - & - \\
\hline 5294 & 117 & 14.05 .98 & 1,25 & 34 & - & - & - & - & - \\
\hline 5296 & 142 & 25.06 .98 & 2,5 & 19 & 12.07.98 & 13 dias & +++ & - & 24.07.98 \\
\hline 5297 & 135 & 25.06 .98 & 2,5 & 32 & - & - & - & - & - \\
\hline 5292 & 151 & 14.07 .98 & 20 & 1 & 17.07.98 & 13 dias & +++ & - & 31.07 .98 \\
\hline 5294 & 119 & 24.07.98 & 10 & 1 & - & - & - & - & - \\
\hline
\end{tabular}

a +++ Intoxicação acentuada, ++ moderada, + leve, - sem sintomas. 
sintomas de intoxicação nos dois bezerros usados, portanto nesta dosagem a planta não mais teve efeito acumulativo.

Os sintomas, bastante uniformes, se iniciaram por diminuição do apetite, diminuição dos movimentos ruminais em quantidade e intensidade, focinho seco e fezes ressequidas. Em seguida observaram-se icterícia, urina de coloração amarelo-ouro a amarelo-escura. Após exposição ao sol, os animais mostravam grande inquietação, representada por balançar e sacudir a cabeça, bater com os pés dos membros posteriores no abdômen, sacudindo as pernas traseiras para trás, pisar no mesmo local (ou bater com os pés), como se tivessem pisando em brasas, dar coices violentos para trás batendo fortemente na parede, lamber muito as partes despigmentadas do corpo afetadas pela fotodermatite, procurar a sombra rapidamente. Apareciam as lesões de fotossensibilização nas partes despigmentadas da superfície do corpo, caracterizadas inicialmente por vermelhidão (congestão), inchação (edema), aparecimento de exsudato na superfície das áreas afetadas, seguidas por formação de fendas e de mumificação da pele nas partes afetadas. Os animais apresentavam andar lerdo, apatia, e ficavam em decúbito esternal com a cabeça encostada no flanco. Em alguns animais observaram-se sialorréia (Bov. 4928, 5249), ranger de dentes (Bov. 4928, 4923, 5249), sintomas nervosos, no Bovino 4928 sob forma de desorientação, estado semelhante a embriaguez, andar em círculos e agressividade, no Bovino 5249 sob forma de instabilidade e andar desequilibrado. $\mathrm{O}$ animal era considerado recuperado, para fins da avaliação do tempo de evolução, quando do desaparecimento da icterícia e da volta integral do apetite; as lesões da pele curadas (cicatrizadas) permaneceram durante longos tempos, às vezes podiam ser vistas ainda após anos.

Os achados de necropsia consistiram no Bovino 4928 em acentuada icterícia generalizada, leve edema subcutâneo na região esternal e dos membros anteriores, conteúdo do rúmen e do omaso ressequido, presença de úlceras na mucosa do abomaso, intestino delgado vazio, cólon com conteúdo ressequido e coberto por muco e fibrina, vesícula biliar distendida com $750 \mathrm{ml}$ de bile, parede da vesícula biliar com uma área espessada com deposição de material fibrinoso, fígado bem amarelado e levemente aumentado de volume e com bordos levemente arredondados, pesando $2.940 \mathrm{~g}$, língua com erosões na face ventral, presença de úlceras na gengiva; no Bovino 4923 foram constatados moderada icterícia generalizada, conteúdo do rúmen e omaso levemente ressequido, abomaso, intestino delgado, ceco e cólon ascendente, vazios, cólon descendente com muito muco, fígado com cor castanho-alaranjada na superfície de corte, lobulação levemente demarcada, na língua e gengiva presença de úlceras.

Ao exame histológico observaram-se, em um animal (Bovino 4928), moderada tumefação e vacuolização difusa de hepatócitos, mais intensa na zona intermediária e necrose coagulativa incipiente nas zonas centrais dos lóbulos hepáticos; havia ainda raros hepatócitos isolados em cariopicnose ou em lise, leve proliferação de fibroblastos nos espaços por- ta e presença de polimorfonucleares em pequena quantidade distribuídos difusamente pelo parênquima hepático. $\mathrm{Na}$ parede da vesícula biliar verificou-se área de necrose delimitada por reação granulomatosa. No rim observou-se nos espaços de Bowman e na luz dos túbulos uriníferos precipitado protéico sob forma de esferas e na luz dos túbulos uriníferos adicionalmente detritos nucleares. No outro animal (Bovino 4923), verificou-se, além de tumefação difusa, hepatócitos isolados ou grupos de hepatócitos, com citoplasma espumoso ou granular, distribuídos aleatoriamente. Ainda havia grande quantidade de inclusões intracitoplasmáticas eosinófilas, homogêneas (corpúsculos de Councilman), distribuídos irregularmente pelo parênquima. Raros hepatócitos em necrose coagultiva incipiente, leve proliferação de fibroblastos nos espaços porta e bilestase ductal e capilar complementaram o quadro histológico do fígado. No cortex renal, as células epiteliais de alguns túbulos uriníferos estavam tumefeitas, com citoplasma granular ou indistinto, com desaparecimento do núcleo (necrose ou lise ). Na luz de túbulos uriníferos havia cilindros hialinos, às vezes com restos nucleares. Na medula, de maneira mais pronunciada na parte próxima ao bacinete, o citoplasma das células epiteliais continham grande quantidade de substância eosinófila homogênea sob forma de grânulos ou pequenas a grandes esferas. No interstício de algumas áreas havia edema e também áreas de calcificação.

\section{DISCUSSÃO E CONCLUSÕES}

Esse estudo confirma que os surtos de intoxicação por lantana em bovinos somente ocorrem em condições especiais, isto é, em gado faminto e transferido de pasto ou região, e de existir uma variedade tóxica de lantana nos pastos em grande quantidade.

Os experimentos com administrações repetidas retificam que plantas do gênero Lantana possuem efeito acumulativo acentuado quando administradas em doses que correspondem a um quarto da dose letal ou a que causa grave intoxicação (Tokarnia et al. 1984), mas mais marcado do que o indicado por Gopinath \& Ford (1969), em cujos experimentos só adoeceram os ovinos que ingeriram a dose tóxica subdividida em duas vezes, mas não quando subdividida em cinco vezes. Um único experimento realizado com a dose letal mais fraccionada, isto é, um oitavo da dose letal por dia durante 22 dias seguidos, indicava que nessa dosagem não haveria mais efeito acumulativo (Tokarnia et al. 1984). No presente estudo a administração de doses repetidas de $5 \mathrm{~g} / \mathrm{kg}(=1 / 8$ da dose letal) e de $2,5 \mathrm{~g} / \mathrm{kg}$ (=1/16 da dose letal), demonstrou ainda nítido efeito acumulativo; mas em um bezerro a última dosagem só teve este efeito após perfazer mais que a dose letal, e em ainda outro bezerro, esta dosagem, mesmo após perfazer duas vezes a dose letal, não causou nem leves sintomas de intoxicação. Doses repetidas de $1,25 \mathrm{~g} / \mathrm{kg} \mathrm{(=1/}$ 32 da dose letal), administradas até completar a dose letal, não mais causaram intoxicação.

As observações de campo indicam que os bovinos mantidos em regiões com lantana não comem em dias sucessivos, as quantidades menores que poderiam causar cumulativamente a intoxicação. 
Agradecimentos.- Ao Prof. Pedro Germano Filho, do Instituto de Biologia, Universidade Federal Rural do Rio de Janeiro, pela identificação do material botânico, ao Dr. Angelo José de Oliveira, veterinário da Emater sediado em Quatis, RJ, pelo apoio que nos tem dado na região da coleta da planta, e à nossa equipe auxiliar, sobretudo ao Assistente de Pesquisa João Luiz Bastos, pela eficiente ajuda na coleta da planta e na execução dos experimentos.

\section{REFERÊNCIAS}

Brito M.F. \& Tokarnia C.H. 1995. Estudo comparativo da toxidez de Lantana camara var. aculeata em bovinos e ovinos. Pesq. Vet. Bras. 15(2/3):79-84.
Gopinath C. \& Ford E.J.H. 1969. The effect of Lantana camara on the liver of sheep. J. Pathol. 99(1):75-85.

Riet-Correa F., Méndez M.C., Schild A.L., Riet-Correa I. \& Silva Neto S.R. 1984. Intoxicação por Lantana glutinosa em bovinos no Estado de Santa Catarina. Pesq. Vet. Bras. 4:147-153.

Seawright A.A. 1965. Toxicity of Lantana spp in Queensland. Aust. Vet. J. 41:235238.

Tokarnia C.H., Döbereiner J., Lazzari A.A. \& Peixoto P.V. 1984. Intoxicação por Lantana spp. (Verbenaceae) em bovinos nos Estados de Mato Grosso e Rio de Janeiro. Pesq. Vet. Bras. 4(4):129-141. 